\title{
Review Article \\ An Excellent Introduction to Diaspora Theory and Transnationalism
}

\author{
Book Name: Diaspora Theory and Transnationalism \\ Author: Himadri Lahiri \\ Genre: Scholarly \\ Publisher: Orient Black Swan \\ Year of Publication: 2019 \\ ISBN: 9789352876143
}

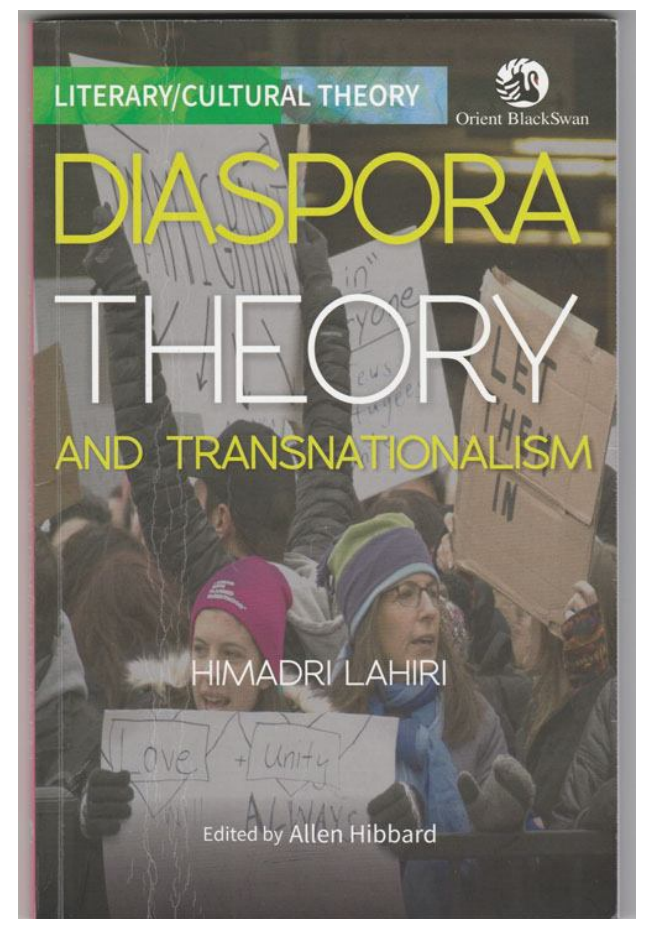

Reviewed by

Suparno Banerjee

Associate Professor of English, Texas State University, San Marcos, TX, USA.

Email:sb67@txstate.edu

While discussing human migration, scholars such as Stuart Hall and Simon Gikandi agree that the absent nation stands for the ideology into which the migrant had been interpellated before his or her journey away from the homeland. Speaking in the context of postcolonial diaspora in the new globalized order, Gikandi (2005) argues that these cultural or national ideologies become objects of transnational border crossings: "in the old global order, the nation was the reality and the category that enabled the socialization of subjects and hence structuralization of cultures; now, in

(c) AesthetixMS 2020. This Open Access article is published under a Creative Commons Attribution Non-Commercial 4.0 International License (http://creativecommons.org/licenses/by-nc/4.0/), which permits non-commercial re-use, distribution, and reproduction in any medium, provided the original work is properly cited. For citation use the DOI. For commercial re-use, please contact editor@rupkatha.com 
transnationality, the nation has become an absent structure" (p. 614). Eschewing of such certainties and categories as "nation" and "national culture" destabilises the identity of the migrant subject. In a world characterized by a constantly mobile population, whether forced or self-willed, a nuanced attention to the phenomena itself perhaps becomes a necessity. Diaspora Theory and studies of transnational cultures serves such a purpose.

Himadri Lahiri's Diaspora Theory and Transnationalism is an important addition to this increasingly important field of study. This relatively brief but multi-faceted study of the two related modes of global population movement and their socio-cultural implications in global demographics fits somewhere between larger anthologies on the topic such as Robin Cohen and Caroline Fisher edited Routledge Handbook of Diaspora Studies (2018) and Kevin Kenny's slim Diaspora: A Very Short Introduction (2013) in Oxford's Very Short Introduction Series. Lahiri's book provides an insight into the broader concepts and trends related to the field, while paying attention to specific historical and cultural instances, and thus introduces the less familiar readers to the field of diaspora theory.

A clear organization is probably the biggest strength of Lahiri's book. Divided into five chapters, an introduction and a conclusion, the book provides a wide view of the field as well as studies specific aspects in depth; in addition, the book examines a work of fiction as a playing field of diasporic politics. In the "Introduction" Lahiri reaches a definition of diaspora by working through the concept's misapplications in intra-national politics and other over-generalizations and establishes the need for maintaining a critical specificity of the term that relates to international movements of population involving "uprooting, forced or voluntary ... from the homeland and their "re-rooting' in hostland(s)" (4). He then lays out the semantic evolution of the term and its application from the ancient times to the present age. A clear comparison with "transnationalism," a term overlapping with "diaspora" but with a more mobile connotation, further clarifies the discursive field for the text. Lahiri's discussion of the types of diaspora similarly proves to be very useful. This categorization from three different perspectives-"the status of the migrants' homeland," historical precedence, and "experience and profession"provides the readers with a broad understanding of global diasporic population. He ends the "Introduction" with a brief discussion of the evolution of diaspora criticism. Primarily based on Sudesh Mishra's non-temporal perspective, this section discusses the major paradigm shifts in diaspora criticism. Combined with Lahiri's etymological and historical discussion of the term at the beginning, these shifting concerns create a comprehensive picture of diaspora theory as a critical lens.

This excellent introductory chapter leads smoothly into the rest of the book, where Lahiri explores specific aspects of diaspora theory in details. These topics include historical stages of diasporic movement, cultural, political, and generational aspects of the diasporic subject, performance of gender and sexuality in diaspora, religion, and mass media and cyberspace.

In Chapter One, following Michele Reis, Lahiri provides a detailed historical account of diaspora in three historical categories: "Classical," "Early Modern," and "Late Modern/Contemporary." Under the first category, Lahiri foregrounds movement of the Jewish people, as well as discusses Greek and Armenian diasporas in the ancient world. The "Early Modern" phase starts with the early colonial activities of European powers in the $16^{\text {th }}$ century. In this section, Lahiri focuses on African and Asian diasporas: primarily forced or coerced movement of people for economic exploitation. His discussion of the civilizational binaries establishes the links between various "labor" diasporas around the world. He not only discusses the African slave 
diasporas in the Black Atlantic, but the "girmit diasporas" of British Empire from the Caribbean to the Pacific islands that originated from South Asia.

Lahiri contrasts the "low-skilled" population of this early modern period with the "highskilled" workers of the "Contemporary/Late Modern" period, which begins after the fall of the Empires, at the conclusion of the World War II, and the rise of US as a global power. He attributes this movement of population from the less developed parts of the world to the developed nations such as US, UK, and Canada to economic globalization. In every instance, Lahiri argues, a "home/homeland" dichotomy underlies the sense of diasporic population's identity. Such concerns do not only stem from nostalgia for the absent space of origin, but the transformation of the absent originary space into a psychological space that shapes the diasporic population's existence in the "hostland." Thus, for Lahiri "transnationalism" and "diaspora" are not exactly synonymous as the former indicates a certain agency of back and forth movement that the later may not possess. Underlining such finer distinctions is necessary for an introductory book such as this, and the author performs that task very well.

Lahiri treats the question of diasporic identity or subject formation in two parts. Chapter Two discusses the matter from generational, cultural and citizenship perspectives, while Chapter Three focuses on gender and sexuality, subjects often ignored in diaspora studies. While all three aspects addressed in Chapter Two are much debated topics in the field, Lahiri's use of the multigenerational Japanese diaspora in the US and their use of specific terminologies to self-identify is especially interesting. This discussion effectively foregrounds the constantly evolving relationship between the immigrant population's "homeland" and "hostland" over generations. Lahiri implies that such evolution exposes the very nature of diasporic and transnational identity formation marked by a dichotomy of isolation and hybridization. While the older generation isolates itself from the host population, the younger generation tends to conform to norms of the receiving society. Such evolving identity leads the discussion of cultural hybridity. Basing his argument on Robert J. C. Young, Paul Gilroy, Mikhail Bakhtin and Homi Bhabha among others, Lahiri shows that such cultural hybridity is not only a mechanism of nostalgia, but a device of future immigrant identities, that is inevitable in zones of contact. Rather than being something degradable and negative, cultural hybridity opens newer possibilities. However, all such generational and cultural questions are undercut by issues of citizenship, especially in the modern western nations, that are not only marked by actual legal implications, but also by ethnic and racist tensions.

This overdetermined nature of diasporic identity is further explored in Chapter Three through the lens of diasporic gender roles and sexual orientations, which according to Lahiri is marked by a predominance of heterosexual patriarchy. Such heterosexual patriarchy not only attempts to control diasporic women's social, marital and reproductive roles related to the immigrant community, but additionally governs diasporic masculinity. In this context, Lahiri highlights the gendered nature of diasporic relationship between the immigrants and the receiving society, wherein such immigrants are often characterized as emasculated or feminine, but at the same time threatening and dangerous. This has been especially true of the recent influx of refugees in Europe, India and US, where typically the male Other is always the lazy freeloader and simultaneously the threatening invader. Lahiri further highlights the restrictions that host societies frequently place on reproductive rights of diasporic groups by controlling their marriage into the host society. Such restrictions are also evident in the economic spheres in such instances as US immigration laws barring spouses (mostly women) of guest workers (mostly men) from seeking employment. However, despite these restrictions the diasporic space often becomes a space of freedom for women coming from more restrictive cultures, due to the availability of a 
dominant culture that does not require women to conform to the culture of their origin. Lahiri notices similar dynamics in sexual expression among the LGBTQ+ community in diaspora.

Chapter Four foregrounds the role of religion in diaspora that Lahiri claims is frequently overshadowed by attention to race and ethnicity. Among the various aspects he discusses the importance of religion as a sustainer of communities in diaspora, especially at the places of worship, is noteworthy. He highlights religion's role not only in reestablishing homeland's culture in the diasporic space and creating a bridge between both locations of the immigrant's existence, but also as a transcendental ideology. This scheme exposes the problems of nomenclature-or hyphenated identities - of the immigrant population: while some diasporas, such as Muslim or Jewish, are explicitly identified by their religion, others, such as African and South Asian diasporas, are geographically or ethnically marked, and hence show the complex ways that all these markers of identity function. Lahiri further discusses transformation of religion-its perception in the host community as well as the practices within the community itself-when translocated. He mentions the specter of Islamophobia in the aftermath the World Trade Center attack and the changes in Sikh religious practices in Britain among other instances to illustrate his point. In other words, this chapter effectively builds on the discussions in the previous chapters and further underscores the overdetermined nature of the diasporic subject's identity.

In Chapter 5, Lahiri provides a 'case study' of Monica Ali's novel Brick Lane, where he applies all the previously discussed categories in reading the novel. This comprehensive textual discussion in conjunction with analyses of other literary works, such as Jhumpa Lahiri's The Namesake and Mohja Kahf's The Girl in the Tangerine Scarf, strewn throughout the other chapters, present Diaspora Theory not only as a topic of social and political concern, but also as a useful lens of literary interpretation.

Lahiri concludes the book with an insightful analysis of the ways electronic media and cyber culture affect and shape the diasporic population. This discussion is especially valuable given the increasingly important roles played by news and social media in generating and manipulating public opinion beyond the borders of any single country. That is, in the era of proliferating electronic communication, transnationalism has taken on a completely new meaning. While the physical world is subjected to cruder forms of constraints, the digital world is still mostly uncontainable. Lahiri's attention to this aspect is highly laudable.

Diaspora Theory and Transnationalism, which includes a "Glossary of Select Terms" and "Texts for Further Reading" at the end of the book, serves its purpose well. In an increasingly globalized world marked by constant flow of population-transnational workers and students, economic migrants, and refugees from relentlessly blooming conflict zones and environmental disasters-examining the effects of such human migration becomes a priority not only in the fields of social sciences but also in literary and cultural studies. Lahiri's book opens the door to the uninitiated and encourages the readers to seek out more.

\section{References}

Gikandi, Simon (2005). Globalization and the Claims of Postcoloniality. In Gaurav Gajanan Desai and Supriya Nair (Eds.), Postcolonialisms: An Anthology of Cultural Theory and Criticism (pp. 608-634). Berg. 